\title{
Use of a Mortality Prediction Model in Children on Mechanical Ventilation: A 5-Year Experience in a Tertiary University Hospital
}

This article was published in the following Dove Press journal: Journal of Multidisciplinary Healthcare

\author{
Waleed H Albuali (D' \\ Amal A Algamdi (iD ${ }^{2}$ \\ Elham A Hasan' \\ Mohammad H Al-Qahtani (D) ' \\ Abdullah A Yousef (iD ${ }^{\prime}$ \\ Mohammad A Al Ghamdi' \\ Dalal K Bubshait ' \\ Mohammed S Alshahrani iD ${ }^{3}$ \\ Faisal O AIQurashi (iD) ' \\ Talal A Bou Shahmah' \\ Bassam H Awary' \\ 'Department of Pediatrics, College of \\ Medicine, King Fahd Hospital of the \\ University, Imam Abdulrahman Bin Faisal \\ University, Dammam, Saudi Arabia; \\ ${ }^{2}$ Department of Family and Community \\ Medicine, College of Medicine, Imam \\ Abdulrahman Bin Faisal University, \\ Dammam, Saudi Arabia; ${ }^{3}$ Emergency and \\ Critical Care Medicine Departments, \\ King Fahd Hospital of the University, \\ Imam Abdulrahman Bin Faisal University, \\ Dammam, Saudi Arabia
}

Correspondence: Faisal O AIQurashi Department of Pediatrics, College of Medicine, King Fahd Hospital of the University, Imam Abdulrahman Bin Faisal University, PO Box I 1286, Dammam

31453, Saudi Arabia

Tel +966555078804

$\mathrm{Fax}+966138955088$

Email Faisal.alqurashi@yahoo.com
Purpose: Currently, several scoring systems for predicting mortality in severely ill children who require treatment in a pediatric intensive care unit (PICU) have been established. However, despite providing high-quality care, children might develop complications that can cause rapid deterioration in health status and can lead to death. Hence, this study aimed to establish a simple early predictive mortality (SEPM) model with high specificity in identifying severely ill children who would possibly benefit from extensive mechanical ventilation during PICU admission.

Patients and Methods: This is a retrospective longitudinal study that included pediatric patients aged older than two weeks who were on mechanical ventilation and were admitted to the PICU of King Fahd Hospital of the University from January 2015 to December 2019.

Results: In total, 400 pediatric patients were included in this study. The mortality rate of children on mechanical ventilation was $28.90 \%$, and most deaths were associated with respiratory $(n=124[31 \%])$, cardiovascular $(n=76[19 \%])$, and neurological $(n=68$ $[17 \%])$ causes. The SEPM model was reported to be effective in predicting mortality, with an accuracy, specificity, and sensitivity of $92.5 \%, 97.31 \%$, and $66.15 \%$, respectively. Moreover, the accuracy, specificity, and sensitivity of the Pediatric Risk of Mortality (PRISM) III score in predicting mortality was $95.25 \%, 98.51 \%$, and $78.46 \%$, respectively.

Conclusion: The SEPM model had a high specificity for mortality prediction. In this model, only six clinical predictors were used, which might be easily obtained in the early period of PICU admission. The ability of the SEPM model and the PRISM III score in predicting mortality in severely ill children was comparable. However, the accuracy of the newly established model in other settings should be validated, and a prospective longitudinal study that considers the effect of the treatment on the model's predictive ability must be conducted.

Keywords: pediatric risk of mortality score, mortality, pediatric intensive care unit, ventilation

\section{Introduction}

The pediatric intensive care unit (PICU) team aims to provide care to severely ill children by applying early extensive interventions and high-quality treatment to achieve better clinical results. The initial assessment of illness is a critical part of PICU evaluation and management. ${ }^{1}$ Currently, multiple scoring systems have been developed for predicting mortality in critically ill patients who are hospitalized. However, children admitted to the PICU might develop complications that can cause rapid deterioration in health status and can lead to death despite the provision 
of high-quality care. Thus, the timely use of a mortality prediction tool can be extremely helpful in settings with severely ill children receiving mechanical ventilation. Preferably, the predictive tool must be established using basic clinical information and must have a high specificity to accurately identify patients with a high chance of survival. Currently, several scoring systems for predicting mortality in patients admitted to the pediatric intensive care unit (PICU) have been developed. In 1988, Adoria et al established the Pediatric Risk of Mortality (PRISM) score, which comprises 14 variables, for predicting mortality in patients admitted to the PICU. ${ }^{2}$ In 1996, Pollack modified the PRISM score to PRISM III score, which has three additional variables. The efficacy of the PRISM III score (17 variables) on 11,165 patients in 32 PICUs across the United States was assessed. The results demonstrate that the tool yielded better results than PRISM in predicting mortality. ${ }^{3}$ Hence, mortality can be predicted using data obtained in $12 \mathrm{~h}$ (PRISM III-12) or $24 \mathrm{~h}$ (PRISM III-24). The PRISM III score is a mortality prediction scale with good predictive ability. ${ }^{3,4}$ However, it requires multiple variables such as blood test results and physiological parameters. ${ }^{5}$ These data might not be accessible during emergency situations or might be difficult to record routinely in PICUs with different resources. In 1997, Shann et al introduced the Pediatric Index of Mortality (PIM) 2 score (updated in 2003) for predicting the outcome of children admitted to PICUs. The PIM 2 score comprises 10 variables. Yes and no responses for these variables were scored as 1 and 0 , respectively. These data were then entered into the system (www.sfar.org/scores2/ pim22.html) to calculate for the predicted mortality rate., The use of the PRISM and PIM 2 scores requires rigorous and specific training and strict adherence to guidelines. Consequently, assessments should be performed by welltrained professionals; however, they can cause wide variabilities in the study. ${ }^{8,9}$

Therefore, this study aimed to develop a simple model for predicting early mortality based on clinical data obtained in the first $24 \mathrm{~h}$ of admission. Moreover, the ability of the newly established model and the PRISMA III score in predicting mortality was compared.

\section{Patients and Methods}

\section{Aim}

This retrospective longitudinal study aimed to establish a simple early predictive mortality (SEPM) model with high specificity for identifying severely ill children who would benefit from extensive mechanical ventilation during admission in the PICU.

\section{Participants}

Pediatric patients aged older than two weeks who were receiving mechanical ventilation and were admitted to the PICU of King Fahd Hospital of the University (KFUH) from January 2015 to December 2019 were included in this study. The PICU of KFUH is a 10-bed multidisciplinary unit that is well equipped with advanced machines that can be used in providing care for infants and children. The unit provides specialized care to patients with complex, surgical, oncological, orthopedic, trauma, and medical care requirements. It serves a community of $\sim 4.9$ million people with $\sim 250$ admissions annually.

Patients admitted for $<24 \mathrm{~h}$, those who died within the first $24 \mathrm{~h}$, those who experienced cardiac arrest before PICU admission, those admitted to the PICU due to burn, and those with incomplete or missing data were excluded from this study. Patients who died within the first $24 \mathrm{~h}$ were excluded because our intended prediction model and the PRISM III scale that was compared with our model require information gathered within the first $12-24 \mathrm{~h}$ of admission; thus, for patients who died within this period, the requisite data to calculate the score would not have been available. In this regard, brain death cases were not excluded because brain death cannot be declared prior to $24 \mathrm{~h}$ of PICU admission as per the policy in Saudi Arabia. ${ }^{10}$

\section{Data}

Data were collected within the first $24 \mathrm{~h}$ of PICU admission and were retrospectively extracted from the medical records. Mortality was calculated at the end of the PICU admission period.

The variables included age (infancy $[\leq 1$ year], toddlerhood [ $>1-2$ years], early childhood $[>2-5$ years], middle childhood [6-11 years], and early adolescence [12-18 years]), gender, cause of PICU admission (respiratory, cardiovascular, or nervous system problems and other medical or surgical conditions), number of organ failure, and sepsis (no, yes). The definition of sepsis was adopted from the recent Surviving Sepsis Campaign guidelines, in which sepsis was defined as "severe infection leading to cardiovascular and/or noncardiovascular organ dysfunction". ${ }^{11}$

Information was obtained on the presence of comorbidities including asthma, chronic lung disease, congestive heart failure, congenital heart disease, cerebral palsy, 
uncontrolled seizures, genetic and metabolic disease variants with CNS involvement, type 1 diabetes mellitus, malignancy, immunodeficiency, thalassemia, sickle cell disease, chronic liver disease, and chronic renal disease, and PRISM III score with 17 physiologic variables subdivided into 26 ranges.

This study was approved by the Institutional Review Board (IRB) of Imam Abdulrahman Bin Faisal University (IRB-2020-01-213). Based on the IRB's Policies of Imam Abdulrahman Bin Faisal University, patients' consents for medical records review purposes are waived for retrospective studies. Furthermore, data confidentiality was ensured following the Declaration of Helsinki principles.

\section{Analysis}

The STATA (version 16) software was used for statistical analyses. The chi-square test, Fisher's exact test, and $t$-test were used to compare the individual characteristics of children who survived and died. Univariate logistic regression analysis was performed to investigate significant variables that might be correlated with mortality in the final prediction model. The final logistic regression model was established using the forward stepwise approach, and the goodness of fit incidences was utilized to examine model fitting (log likelihood ratio, adjusted R2, Bayesian information criterion [BIC], Akaike information criterion [AIC], and receiver operating characteristic [ROC]). The Wald test and likelihood ratio test were used to compare the nested models. The ability of the final prediction model was examined using the ROC curve and the classification table. Moreover, the Hosmer-Lemeshow test was utilized to examine model fitting using 10 random subgroups. The collinearity among continuous and explanatory variables was examined using the correlation matrix, scatter plot, and variance inflation. The risk of mortality was calculated using the following equation:

$$
p=\frac{\mathrm{e}^{\left(\beta_{0}+\beta_{1} \mathrm{x}_{1}+\ldots+\beta_{\mathrm{k}} \mathrm{x}_{\mathrm{k}}\right)}}{1+\mathrm{e}^{\left(\beta_{0}+\beta_{1} \mathrm{x}_{1}+\ldots+\beta_{\mathrm{k}} \mathrm{x}_{\mathrm{k}}\right)}}
$$

\section{Results}

\section{Study Participants}

Of the 1319 patients admitted to the PICU, only 400 were included in the analysis; $93.70 \%(n=922)$ of the excluded patients were not put on ventilators while the remaining $6.30 \%(\mathrm{n}=62)$ patients were excluded because of other exclusion criteria (Figure 1).
The incidence rate of mechanical ventilation among children admitted to the PICU within the last 5 years was $28.90 \%(n=400)$. The mortality rate was $16.25 \%(n=65)$, and $20 \%$ of children who died were toddlers. The major causes of PICU admission were respiratory, cardiac, and renal problems. Trauma-related admissions were mainly attributed to head injuries ( $\mathrm{n}=14,3.6 \%$ ), and $69 \%$ of children with trauma were aged below 5 years. Moreover, $\sim 50 \%$ of deceased children had complications such as sepsis and/or multiple organ failure; 60\% $(n=39)$ of patients admitted to the PICU died after an unsuccessful cardiac pulmonary resuscitation $(\mathrm{CPR})$ and $24 \%(\mathrm{n}=16)$ were found to be brain dead upon evaluation after $24 \mathrm{~h}$ of admission to the PICU. Furthermore, the parents of $10(15 \%)$ patients signed the do not resuscitate request form, and these patients did not further receive escalation therapy.

The mean number of PICU admission days of all participants was 11.66 (standard deviation $[\mathrm{SD}]=7.09$; $\max =$ 32 , $\min =2$ ). The mean number of PICU admission days was significantly higher in the deceased children (15.77 [SD $=7.07]$; $\max =31, \min =5$ ) than in those who survived $(10.86[\mathrm{SD}=6.82] ; \max =32, \min =2 ; \mathrm{t}(398)=5.277 ; \mathrm{P}<$ $0.001)$. Additionally, the mean number of total ventilation days of all participants was $7.92(\mathrm{SD}=9.14$; $\max =46, \min$ $=2$ ); the mean ventilation days in the deceased children was $14.14(\mathrm{SD}=6.33 ; \max =25, \min =4)$, whereas in the children who survived, it was $6.71(\mathrm{SD}=2.61$; $\max =17$, $\min =2$ ). There was a significant difference in the number of inotropes received between the deceased patients $($ Mode $=2$; mean $=2.03[\mathrm{SD}=1.16] ; \min =0, \max =4)$ and those who survived $($ Mode $=1 ;$ mean $=1.06[\mathrm{SD}=1.04]$; $\min =0$, $\max$ $=3 ; \mathrm{z}=-6.000 ; \mathrm{P}<0.001)$. The mean weight of the deceased patients was $19.6 \mathrm{~kg}(\mathrm{SD}=11.93$; $\max =43$, $\min$ $=4)$ and that of those who survived was $23.2 \mathrm{~kg}$ ( $\mathrm{SD}=$ 11.84; $\max =55, \min =5 ; \mathrm{t}(398)=2.24, \mathrm{P}=0.026)$. The deceased children $($ mean $=17.57, \mathrm{SD}=2.91, \max =28$, min =6) had a significantly higher mean PRISM III score than children who survived $($ mean $=6.51, \mathrm{SD}=5.84 ; \max =17$, $\min =0 ; \mathrm{t}(398)=22.97 ; \mathrm{P}<0.001)$. There was no statistically significant difference between children who survived and those who did not in terms of age and sex. The individual characteristics and distribution between children who survived and those who did not are presented in Table 1.

\section{Mortality Prediction Model} Model Selection

First, a univariate logistic regression analysis was performed to assess the risk of mortality before using the 


\section{Children \\ Were admitted between January 2015 to December 2019.}

\begin{tabular}{|l|}
400 were included in the study \\
335 survived \\
65 deceased \\
\hline
\end{tabular}

62 were excluded

I. Admitted in PICU for less than 24 hours.

II. Died within the first 24 hours of PICU admission.

III. Age was $<2$ weeks or $>14$ years.

IV. Had cardiac arrest before PICU admission.

V. Incomplete or missing data.

VI. Children with burn.

Figure I Schematic illustration of the patient selection criteria

Note: A total of 400 children who were ventilated in the pediatric intensive care unit over the past 5 years were included.

forward stepwise adjustment approach in selecting study variables or interaction terms that will be included in the prediction model. The various examined interaction terms were between the following study variables: weight, age, gender, and comorbidities; however, these interaction terms were not statistically significant or did not improve the prediction model goodness-of-fit statistics.

The final model was the nested model that included four categorical variables (cause of admission, comorbidity, sepsis, and age categories) and two continuous variables (number of organ failure and weight). Sex as well as interaction terms of variables were not included in this model because they did not improve the model fitting statistics.

This chosen SEPM model had the lowest likelihood ratio (177), $\mathrm{BIC}(-2128)$, and $\mathrm{AIC}$ (212) and highest adjusted R2 (McFadden's R2 $=0.402$, Cragg-Uhler's R2 $=0.591$, and Efron's R2 $=0.542$ ).

\section{Predictive Ability of the Simple Early Predictive Mortality Model (SEPM)}

The ROC curves for the SEPM model and the PRISM III score is presented in Figure 2. The SEPM model showed an excellent predictive ability (area under the curve $[\mathrm{AUC}]=0.916$; $95 \%$ confidence interval $[\mathrm{CI}]=0.872,0.958)$. Although the area under the ROC curve of the SEPM model was not superior to that of the PRISM III score (AUC $=0.955 ; 95 \% \mathrm{CI}=$ $0.924,0.986)$, there was no significant difference between the AUC of the two models $\left(\mathrm{X}^{2}(1)=2.22 ; \mathrm{P}=0.136\right)$.

The PRISM III score showed an excellent discrimination ability using a cutoff point of $\geq 12$ (sensitivity: 
Table I Distribution of Individual Characteristics in Relation to Mortality Rate

\begin{tabular}{|c|c|c|c|c|c|c|c|c|}
\hline \multirow[t]{2}{*}{$\begin{array}{l}\text { Characteristics of the } \\
\text { Participants }\end{array}$} & \multicolumn{2}{|c|}{$\begin{array}{l}\text { Patients Who } \\
\text { Survived }\end{array}$} & \multicolumn{2}{|c|}{$\begin{array}{l}\text { Deceased } \\
\text { Patients }\end{array}$} & \multirow{2}{*}{$\begin{array}{l}\text { Total Number of } \\
\text { Participants } \\
N=400\end{array}$} & \multirow[t]{2}{*}{$x^{2}$} & \multirow[t]{2}{*}{$d f$} & \multirow[t]{2}{*}{$P$ value } \\
\hline & $(N=335)$ & $\%$ & $(N=65)$ & $\%$ & & & & \\
\hline Age (NICHD classification) & & & & & & & & $0.773^{*}$ \\
\hline Infancy $(\leq$ I year $)$ & 87 & 87.00 & 13 & 13.00 & 100 & & & \\
\hline Toddlerhood (>I-2 years) & 54 & 79.41 & 14 & 20.59 & 68 & & & \\
\hline Early childhood (>2-5 years) & 90 & 83.33 & 18 & 16.67 & 108 & & & \\
\hline Middle childhood (6-II years) & 80 & 83.33 & 16 & 16.67 & 96 & & & \\
\hline Early adolescence (12-18 years) & 24 & 85.71 & 4 & 14.29 & 28 & & & \\
\hline Gender & & & & & & 2.21 & $\mathrm{I}$ & 0.137 \\
\hline Male & 183 & 81.33 & 42 & 18.67 & 225 & & & \\
\hline Female & 152 & 86.86 & 23 & 13.14 & 175 & & & \\
\hline Comorbidity & & & & & & 19.40 & 1 & $<0.001$ \\
\hline Yes & 230 & 89.84 & 26 & 10.16 & 256 & & & \\
\hline No & 105 & 72.92 & 39 & 27.08 & 144 & & & \\
\hline Cause of PICU admission & & & & & & & & $<0.001 *$ \\
\hline Respiratory problems & 97 & 78.23 & 27 & 21.77 & 124 & & & \\
\hline Cardiac problems & 58 & 76.32 & 18 & 23.68 & 76 & & & \\
\hline Central nervous system problems & 57 & 83.82 & 11 & 16.18 & 68 & & & \\
\hline Others & & & & & & & & \\
\hline - Endocrine diseases & 25 & 100 & 0 & 0.00 & 25 & & & \\
\hline - Gastrointestinal diseases & 33 & 100 & 0 & 0.00 & 33 & & & \\
\hline - Renal diseases & 16 & 76.19 & 5 & 23.81 & 21 & & & \\
\hline - Hematological disorders & 8 & 100 & 0 & 0.00 & 8 & & & \\
\hline - Surgical conditions & 20 & 100 & 0 & 0.00 & 20 & & & \\
\hline - Others & 21 & 84.00 & 4 & 16.00 & 25 & & & \\
\hline Number of organ failure & & & & & & 100.50 & 2 & $<0.001$ \\
\hline One & 217 & 99.09 & 2 & 0.91 & 219 & & & \\
\hline Two & 69 & $78.4 I$ & 19 & 21.59 & 88 & & & \\
\hline Three or more & 49 & 53.26 & 43 & 46.74 & 92 & & & \\
\hline Sepsis & & & & & & 7.87 & 1 & 0.005 \\
\hline No & 207 & 88.09 & 28 & $11.9 \mid$ & 235 & & & \\
\hline Yes & 128 & 77.58 & 37 & 22.42 & 165 & & & \\
\hline
\end{tabular}

Notes: $* P$ value from the Fisher's exact test. The chi-square test and Fisher's exact test were used to examine differences in the distribution of categorical variables between participants who survived and those who did not.

84.62\%, specificity: $96.12 \%$, classification ability: 94.25\%, positive likelihood ratio: 21.80 ; and negative likelihood ratio: 0.16). Our SEPM model showed an excellent classification ability $(92.25 \%)$ using the probability cutoff value of 0.5 (Table S1). However, the cutoff points could be changed to improve either the specificity or the sensitivity, as required (Figure 3). Using the probability cutoff of 0.5 , the specificity of the SEPM model was $97.31 \%$, sensitivity was $66.15 \%$, positive predictive value was $82.69 \%$, and negative predictive value was $93.68 \%$ (Table S2).
Table 2 presents a summary of the model's coefficients and ORs in the chosen SEPM prediction model. This SEPM model had a statistically significant goodness of fit statistics using the log likelihood ratio test, Wald test, and Hosmer-Lemeshow test with 10 random groups.

\section{Discussion}

Our study aimed to predict mortality among ventilated children admitted to the PICU. Mechanical ventilation is the most common technology used to support severely ill children in the PICU, and its use might imply a higher 


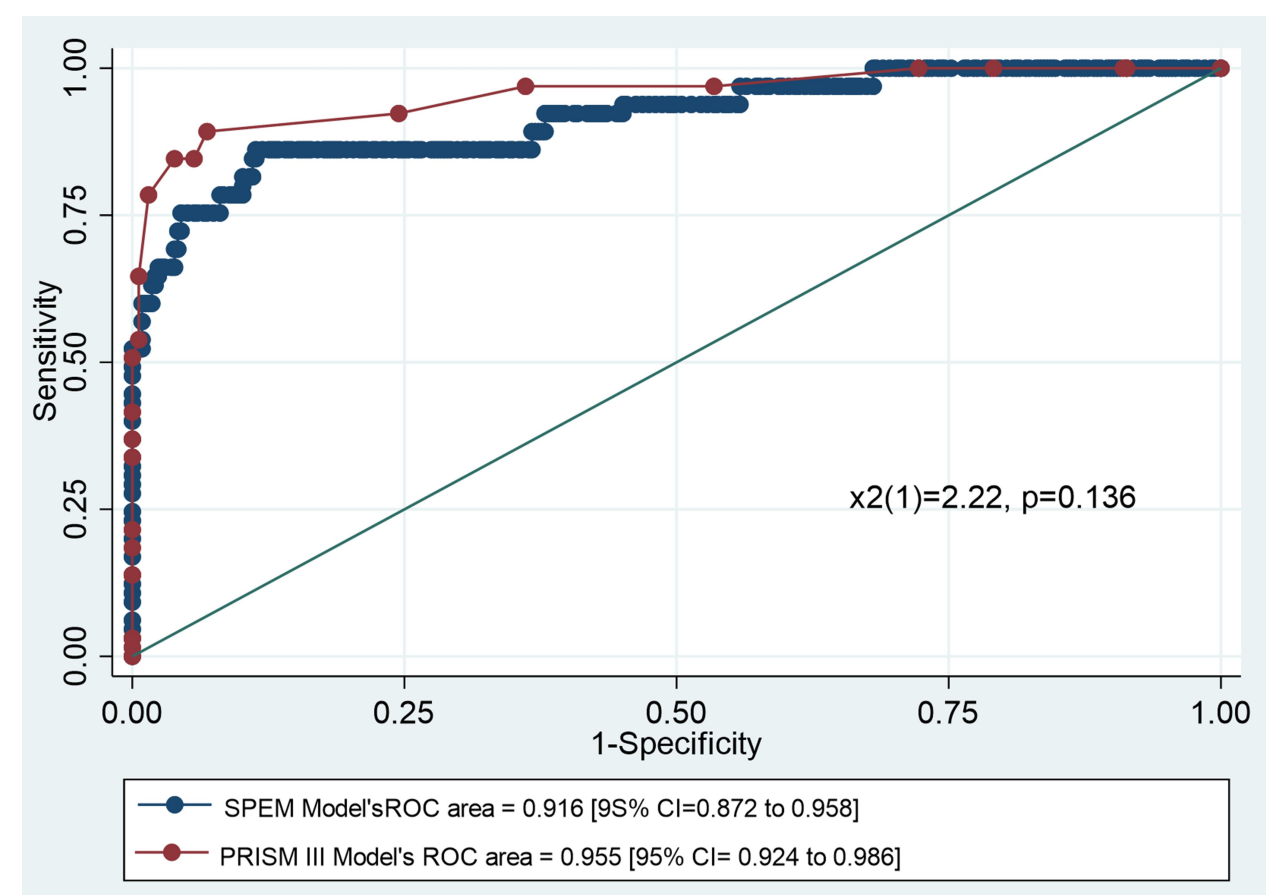

Figure 2 Receiver operating characteristic curve for the SEPM model and PRISM III score.

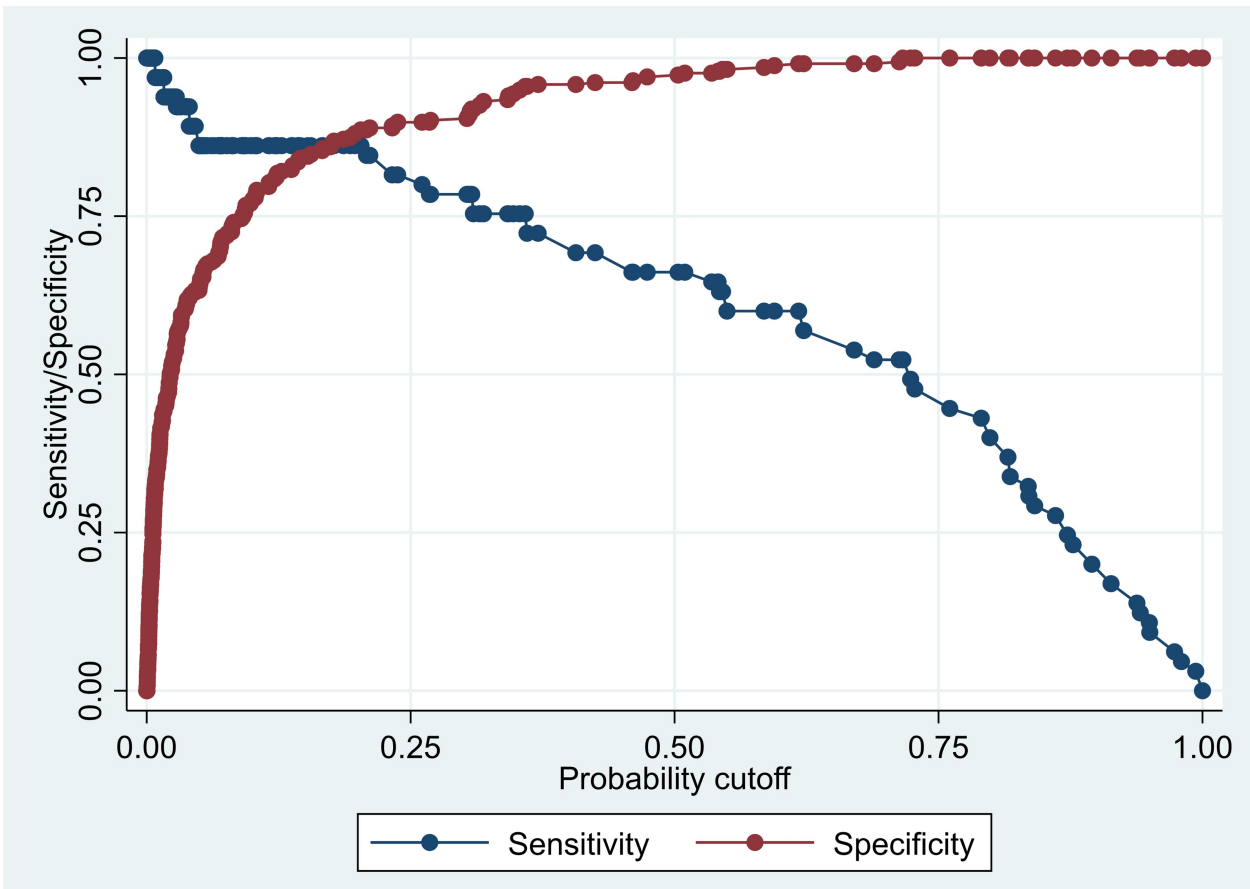

Figure 3 Line graph showing the sensitivity and specificity of the SEPM model according to several cutoff points for the predictive probability.

disease severity. However, the incidence rate of mechanical ventilation in our unit was $28.9 \%$. This rate was acceptable considering that the proportion of children on mechanical ventilation in PICUs vary widely from $17 \%$ to
$60 \% .{ }^{12-16}$ In this study, the mortality rate among children on mechanical ventilation in the PICU was $16.25 \%$, and this is comparable to that reported in the literature. However, most patients were lost after an aggressive 
Table 2 Summary of SEPM Model Estimates and Statistics

\begin{tabular}{|c|c|c|c|c|c|c|c|c|}
\hline Variables & Given Code & Coefficient & SE & $\mathbf{z}$ & $P$ value & OR & Lower Cl & Upper Cl \\
\hline Weight (kg) & $\mathrm{kg}$ & -0.12 & 0.03 & -4.35 & $<0.001$ & 0.88 & 0.84 & 0.93 \\
\hline \multicolumn{9}{|l|}{ Age } \\
\hline Infancy ( $\leq$ I year) & 0 & Reference & & & & & & \\
\hline Toddlerhood (>I-2 years) & 1 & 1.53 & 0.64 & 2.40 & 0.016 & 4.60 & 1.32 & 15.99 \\
\hline Early childhood (3-5 years) & 2 & 2.65 & 0.76 & 3.48 & $<0.001$ & 14.19 & 3.19 & 63.17 \\
\hline Middle childhood (6-1I years) & 3 & 2.83 & 0.83 & 3.39 & 0.001 & 16.93 & 3.30 & 86.80 \\
\hline Early adolescence (12-18 years) & 4 & 1.94 & 1.23 & 1.58 & 0.115 & 6.97 & 0.62 & 78.08 \\
\hline \multicolumn{9}{|l|}{ Comorbidity } \\
\hline No & 0 & Reference & & & & & & \\
\hline Yes & 1 & 1.26 & 0.42 & 2.99 & 0.003 & 3.52 & 1.55 & 8.04 \\
\hline \multicolumn{9}{|l|}{ Cause of admission } \\
\hline Others & 0 & Reference & & & & & & \\
\hline Respiratory problems & 1 & 1.70 & 0.61 & 2.79 & 0.005 & 5.50 & 1.66 & $|8.2|$ \\
\hline Cardiac disorders & 2 & 2.08 & 0.65 & 3.22 & 0.001 & 8.00 & 2.25 & 28.39 \\
\hline CNS disease & 3 & 1.24 & 0.71 & 1.74 & 0.082 & 3.46 & 0.85 & 13.98 \\
\hline Number of organ failure & Number & 1.86 & 0.25 & 7.37 & $<0.001$ & 6.40 & 3.91 & 10.49 \\
\hline \multicolumn{9}{|l|}{ Sepsis } \\
\hline No & 0 & Reference & & & & & & \\
\hline Yes & 1 & 0.96 & 0.40 & 2.42 & 0.016 & 2.61 & 1.20 & 5.66 \\
\hline Constant & & -7.26 & 0.99 & -7.29 & $<0.001$ & 0.001 & 0.000 & 0.005 \\
\hline Model fitting evaluation statistics & & & $d f$ & $x^{2}$ & P value & & & \\
\hline Likelihood test & & & 11 & 170.86 & $<0.001$ & & & \\
\hline Wald test & & & II & 74.01 & $<0.001$ & & & \\
\hline Hosmer-Lemeshow test (10 groups) & & & 8 & 25.93 & 0.001 & & & \\
\hline
\end{tabular}

Abbreviations: SEPM, simple early predictive mortality model; PICU, pediatric intensive care unit; KFUH, King Fahd University Hospital; PRISM, Pediatric Risk of Mortality Score; PIM, Pediatric Index of Mortality; BIC, Bayesian Information Criterion; AIC, Akaike Information Criterion; ROC, receiver operating characteristic; CPR, cardiac pulmonary resuscitation.

CPR or after being diagnosed as brain dead. These results differed from those of a study conducted in the United States. That is, the research showed that $70 \%(n=133)$ of PICU patients died after withdrawal from life-sustaining treatments. ${ }^{17}$ These differences in resuscitation decisions and withdrawal from life-sustaining treatment might be attributed to our culture. That is, there is a limited understanding on Islamic laws and ethics regarding end-of-life decisions that allow withdrawal of life support machines in children who are terminally ill and who are about to die. ${ }^{18}$ In addition, as per the Saudi Policy, brain death cannot be declared in pediatric patients before $24 \mathrm{~h}$ of admission to the PICU. ${ }^{10}$ However, this period can be further extended depending on the underlying cause of admission and the extent of injuries, which make it difficult to make an early decision on withdrawal of life support machines. ${ }^{10}$ Furthermore, in our study, respiratory (such as pneumonia and bronchiolitis) and cardiovascular diseases were the most common causes of PICU admission and mechanical ventilation. This finding can be attributed to the fact that these conditions are prevalent among children, particularly those aged below 5 years, in Saudi Arabia. These results are similar to those of studies conducted in other countries, which showed that respiratory and cardiovascular diseases are the two major causes of admission among children in the PICU. ${ }^{8,19}$

This study aimed to establish a simple model for predicting early mortality within $24 \mathrm{~h}$ of admission among severely ill children receiving mechanical ventilation in the PICU. The model used the minimum number of required clinical information to facilitate decision making within a short period. Our model included six clinical data such as weight, age categories, presence of comorbidity, cause of PICU admission, number of organ failure, and severity of sepsis. The 
accuracy, specificity, and sensitivity of this model were $92 \%$, $97 \%$, and $66 \%$, respectively, using a cutoff probability value of 0.5 . Moreover, the accuracy, specificity, and sensitivity of the PRISM III score were 95.25\%, 98.51\%, and 78.46\%, respectively, using a cutoff point of $\geq 14$. The results of the current study were comparable to those of published research in the literature. However, these studies revealed a lower classification ability ranging from $89.2 \%$ to $92 \%$. ${ }^{9,20-22}$ Furthermore, another study was conducted on patients with meningococcal infections admitted to the PICU. The results showed a higher AUC for ROC (0.94), which might indicate that the predictive ability of the PRISM III score could be enhanced by illness severity, as in our case. ${ }^{23}$ The PRISM III score might directly reflect illness severity rather than death if it was calculated in the early period of admission to the PICU (ie, in the first 12-24 h). Thus, it has a high predictive ability among extremely sick children. ${ }^{6}$ Our model used clinical and demographic data obtained in the first $24 \mathrm{~h}$ of admission, which is the period wherein the PRISM III score is routinely calculated. However, the model depends on variables such as severity of sepsis and number of organ failure, not physiological and laboratory parameters, which may vary widely when obtained during the same time frame. Moreover, the accuracy of the PRISM III score might be influenced by study design. That is, in another PICU study, the AUC for the PRISM III score obtained 12 and $24 \mathrm{~h}$ after admission was $0.78(95 \% \mathrm{CI}=0.67,0.89)$. Moreover, that for the PIM2 score was $0.74(95 \% \mathrm{CI}=0.63,0.85)$ when a prospective rather than a retrospective design was used. This result might indicate that a retrospective study design could cause an overestimation of mortality prediction because of precision error in collecting data during events. $^{24}$ The PIM2 score, which uses both clinical and laboratory data, is usually performed within $1 \mathrm{~h}$ of PICU admission. However, the patient's condition might rapidly change after providing hemodynamic support; thus, predictive ability might be affected by the level of management in PICU. The use of PIM2 and PRISM scores, unlike our model, requires training to ensure adherence to treatment guidelines. Thus, this might limit the number of professional staff who could perform the assessment using the scoring system and could enhance the wide variability in results. ${ }^{25}$ The high specificity (97.31\%) and negative predictive value (93.68\%) could have helped in identifying children who have a high chance of survival and who are likely to benefit from therapeutic interventions. However, the model had a low sensitivity (65.6\%). This outcome might be influenced by PICU interventions provided after admission. Hence, the actual mortality rate among children who had a risk of dying at the time of admission decreased. This result might indicate that the PICU team had a good performance, which led to the high possibility of false-positive rates. Nevertheless, in this context, our model might be a useful quality assessment tool for assessing care provided in PICUs.

To our knowledge, this is the first study that used a simple model for predicting mortality among severely ill children who are on mechanical ventilation in this ethnic group. The current study had several limitations. That is, it was conducted at a single center. Furthermore, only a small number of patients were included, and most patients were Arabs. Thus, the model's performance might differ when applied to another population. However, the PICU of this university hospital receives referrals from all over the eastern province of the Kingdom of Saudi Arabia. Hence, the results could be generalized on a wide region in the country. Moreover, there were no external validation data that can be used to confirm the accuracy of our model, and this is considered another important limitation. However, if external data can show that our prediction model had inappropriate fitting, it will be difficult to assess whether this was attributed to differences in context information found in other hospital sittings or to the limited prediction ability of the model itself. Nevertheless, additional studies should be conducted to assess our model. Moreover, its prediction ability must be enhanced by modifying variable categorization using other significant clinical variables that were not included in our model. These variables include admission pathway (ie, pediatric ward and ER), pupil's reaction to light, and length of hospital stay before starting ventilation in the PICU. Our model could accurately classify patients using a probability cutoff point of 0.5 and using only six variables. Therefore, it is comparable to the PRISM III score. However, the model was more simple in term of the number of variables used and the availability and accessibility of these variables particularly during emergency situations or family consultations. The prediction model was used on severely ill children who were receiving mechanical ventilation. However, future studies should utilize this model on other PICU patients, such as those who are not on mechanical ventilation. Finally, as previously discussed, the ability of prediction models might be affected by interventions provided in the PICU and possible measurement errors associated with a retrospective study design. Hence, in the future, a prospective study should be performed to examine the ability of prediction models during several periods in PICU admission and to evaluate whether treatments affected the model's predictive ability. In 
addition, we recommend comparing the prediction ability of our model against that of other validated prediction models such as PIM2 and PIM3. We could not perform this analysis due to the retrospective nature of our study and the possibility of developing time reporting error for some variables during data extraction.

\section{Conclusion}

The SEPM model had a high specificity in predicting mortality using only six clinical predictors that might be obtained easily in the early period of PICU admission. In addition, the prediction ability of the SEPM model and the PRISM III score was comparable. That it, they had an excellent mortality prediction ability in severely ill children. Finally, further research should be conducted to validate the new SEPM model using an external dataset and a prospective longitudinal design that can consider the effect of treatment on the model's prediction ability.

\section{Acknowledgments}

We would like to thank Cecile Ordone-De Guia, MD. for assisting in data collection.

\section{Disclosure}

The authors report no conflicts of interest in this work.

\section{References}

1. Pollack MM, Rutiman UE, Getson PR, et al. Accurate prediction of the outcome of Pediatric Intensive care. $N$ Engl $J$ Med. 1987;316:134-139. doi:10.1056/NEJM198701153160304

2. Adoria P, Bhagwat AG. Severity scoring systems in paediatric intensive care units. Indian J Anaesth. 2008;52(5):663-675.

3. Pollack MM, Ruttimann UE, Getson PR. Pediatric risk of mortality (PRISM) score. Crit Care Med. 1988;16(11):1110-1116. doi:10.1097/ 00003246-198811000-00006

4. Pollack MM, Patel KM, Ruttimann UE. PRISM III: an updated Pediatric Risk of Mortality score. Crit Care Med. 1996;24 (5):743-752. doi:10.1097/00003246-199605000-00004

5. Costa GA, Delgado AF, Ferraro A, et al. Application of the pediatric risk of mortality (PRISM) score and determination of mortality risk factors in a tertiary pediatric intensive care unit. Clinics. 2010;65 (11):1087-1092. doi:10.1590/S1807-59322010001100005

6. Shann F, Pearson G, Slater A, et al. Paediatric index of mortality (PIM): a mortality prediction model for children in intensive care. Intens Care Med. 1997;23(2):201-207. doi:10.1007/s001340050317

7. Sankar J, Chandel A, Dubey NK, et al. Do interventions in an ICU affect the predictive ability of pediatric index of mortality and pediatric index of mortality-2 scores in a tertiary care hospital? Pediatr Crit Care Med. 2013;14(2):e70-76. doi:10.1097/PCC.0b013e31827127cd
8. Taori RN, Lahiri KR, Tullu MS. Performance of PRISM (Pediatric Risk of Mortality) score and PIM (Pediatric Index of Mortality) score in a tertiary care pediatric ICU. Indian $J$ Pediatr. 2010;77 (3):267-271. doi:10.1007/s12098-010-0031-3

9. Karambelkar GR, Mane SV, Agarkhedkar SR, et al. The relevance of 24 hour PRISM III score in predicting mortality in pediatric intensive care unit. Int J Pharm Biomed Sci. 2012;3.

10. Jan MM. Brain death criteria. The neurological determination of death. Neurosciences (Riyadh). 2008;13(4):350-355.

11. Weiss SL, Peters MJ, Alhazzani W, et al. Surviving sepsis campaign international guidelines for the management of septic shock and sepsis-associated organ dysfunction in children. Intensive Care Med. 2020;46(Supp11):10-67.

12. Farias JA, Frutos F, Esteban A, et al. What is the daily practice of mechanical ventilation in pediatric intensive care units? A multicenter study. Intens Care Med. 2004;30(5):918-925. doi:10.1007/s00134-004-2225-5

13. Wolfler A, Calderoni E, Ottonello G, et al. Daily practice of mechanical ventilation in Italian pediatric intensive care units: a prospective survey. Pediatr Crit Care Med. 2011;12(2):141-146. doi:10.1097/ PCC.0b013e3181dbaeb3

14. Randolph AG, Meert KL, O'Neil ME, et al. The feasibility of conducting clinical trials in infants and children with acute respiratory failure. Am J Respir Crit Care Med. 2003;167(10):1334-1340. doi:10.1164/rccm.200210-1175OC

15. Kendirli T, Kavaz A, Yalaki Z, et al. Mechanical ventilation in children. Turkish J Pediatr. 2006;48(4):323.

16. Mukhtar B, Siddiqui NR, Haque A. Clinical characteristics and immediate-outcome of children mechanically ventilated in PICU of Pakistan. Pak J Med Sci. 2014;30:927-930.

17. Burns JP, Sellers DE, Meyer EC, et al. Epidemiology of death in the pediatric intensive care unit at five US teaching hospitals. Crit Care Med. 2014;42(9):2101. doi:10.1097/CCM.0000000000000498

18. Chamsi-Pasha H, Albar MA. Do not resuscitate, brain death, and organ transplantation: islamic perspective. Avicenna J Med. 2017;7 (2):35.

19. Yang WC, Lin YR, Zhao LL, et al. Epidemiology of pediatric critically-ill patients presenting to the pediatric emergency department. Klin Padiatr. 2013;225:18-23.

20. Bellad R, Rao S, Patil VD, et al. Outcome of intensive care unit patients using pediatric risk of mortality (PRISM) score. Indian Pediatr. 2009;46(12):1091-1092.

21. El-Nawawy A. Evaluation of the outcome of patients admitted to the pediatric intensive care unit in Alexandria using the pediatric risk of mortality (PRISM) score. J Trop Pediatrics. 2003;49(2):109-114. doi:10.1093/tropej/49.2.109

22. Choi KM, Ng DK, Wong SF, et al. Assessment of the Pediatric Index of Mortality (PIM) and the Pediatric Risk of Mortality (PRISM) III score for prediction of mortality in a paediatric intensive care unit in Hong Kong. Hong Kong Med J. 2005;11(2):97-103.

23. Van Brakel MJ, Van Vught AJ, Gemke RJ. Pediatric risk of mortality (PRISM) score in meningococcal disease. Eur J Pediatr. 2000;159 (4):232-236. doi:10.1007/s004310050060

24. Gemke RJ, van Vught JA. Scoring systems in pediatric intensive care: PRISM III versus PIM. Intens Care Med. 2002;28 (2):204-207. doi:10.1007/s00134-001-1185-2

25. Van Keulen JG, Polderman KH, Gemke RJ. Reliability of PRISM and PIM scores in paediatric intensive care. Arch Dis Child. 2005;90 (2):211-214. doi:10.1136/adc.2003.046722 


\section{Publish your work in this journal}

The Journal of Multidisciplinary Healthcare is an international, peerreviewed open-access journal that aims to represent and publish research in healthcare areas delivered by practitioners of different disciplines. This includes studies and reviews conducted by multidisciplinary teams as well as research which evaluates the results or conduct of such teams or healthcare processes in general. The journal covers a very wide range of areas and welcomes submissions from practitioners at all levels, from all over the world. The manuscript management system is completely online and includes a very quick and fair peer-review system. Visit http://www.dovepress.com/testimonials. php to read real quotes from published authors. 